\title{
Os Caminhos da Pragmática no Brasil
}

(Pragmatic Studies in Brazil)

Kanavillil Rajagopalan (Universidade Estadual de Campinas)

ABSTRACT: This paper traces the history of the study of pragmatics in Brazil. It is shown that Brazilian researches have, by and large, remained attentive to major developments in the field taking place elsewhere in the world. Of particular importance is the burgeoning tendency to focus attention on social issues affecting the day-to-day lives of ordinary people. More and more researchers are realizing the need to assume a critical role in relation to the theories they encounter in the literature.

KEY WoRDs: Pragmatics; Semantics; Linguistic Theory; Linguistic Research in Brazil.

Palavras-Chave: Pragmática; Semântica; Teoria Lingüística; Pesquisa Lingüística no Brasil.

São vários os fatores que dificultam qualquer tentativa de averiguar as pesquisas no campo da pragmática no Brasil. O primeiro e o mais importante deles nada tem a ver com as condições sabidamente precárias de pesquisa no país, mas sim à própria indefinição a respeito do que vem a ser a pragmática ou seja, trata-se de algo que atinge todos os pesquisadores no mundo inteiro. Ao apresentar um volume de artigos dedicados à pragmática, publicado em 1983, Vogt (1983: 7) já avisava: "Hoje a pragmática são muitas coisas, sem ser nenhuma em especial". Passadas uma década e meia, a situação permanece inalterada, como bem evidencia a afirmação feita pelo presente autor no texto de apresentação ao número 30 dos Cadernos de Estudos Lingüísticos da Unicamp, dedicado à pragmática: "A pragmática ainda é vista por muitos estudiosos, não sem razão, como um verdadeiro saco de gatos" (Rajagopalan, 1996: 6), ou ainda, "O interesse da pragmática, para mim, sempre foi a inexistência da disciplina propriamente dita - na verdade, parece muito mais sensato falar em pragmáticas, no plural".

Na mesma coletânea apresentada por Vogt, constava um artigo de Guimarães no qual o autor abria a discussão dizendo o seguinte: "Os estudos sobre a linguagem têm sido incluídos há muito e, de modo mais intenso, nos últimos 30 anos, estudos que têm sido colocados como o objeto da pragmática. No entanto tais estudos, como de resto qualquer outro tipo de reflexão sobre 
a linguagem, não se apresenta, e nem poderia, como um conjunto monolítico e único." (Guimarães, 1983: 15). Trata-se, na verdade, de um outro fator que dificulta qualquer esforço de relatar as pesquisas na área da pragmática: não existe, nem de longe, nenhum consenso sobre como e quando surgiu a área de investigação. De acordo com Guimarães, "para não sair dos limites relativos ao tempo da chamada lingüística moderna, podemos dizer que [a história da pragmática] remonta ao filósofo americano Charles S. Peirce" (ibid.). No entanto, segundo o Penguin Dictionary of Philosophy (Mautner, 1996), o termo 'pragmática' se estabeleceu a partir dos anos 1930, graças aos esforços de Charles Morris. Levinson concorda, porém faz questão de ressaltar que "Além dessa ligação, há muito pouca relação entre a pragmática e as doutrinas filosóficas de pragmatismo" (1983: 1). Nas palavras de Lyons (1977: 119), "Decerto, pode-se argumentar que as origens da distinção tripartiste [sintaxe, semântica, pragmática] na concepção peirceana da ciência geral de semiótica são, hoje em dia, mais ou menos irrelevantes quanto ao modo como essa distinção é traçada pelos lingüistas e filósofos". Na contramão desses estudiosos estão Brigitte Nehrlich e David Clarke que, em seu livro relativamente recente (Nehrlich \& Clarke, 1996), se esforçam para procurar achar as raízes da pragmática contemporânea nos fins do século XVIII.

Gazdar (1979: 2) nos dá uma excelente dica sobre o porquê de tamanha indefinição em torno do uso do termo 'pragmática': “... nos 30 anos que se passaram entre a monografia de Morris e o trabalho de Montague intitulado 'Pragmática', quase ninguém estudou nada que o próprio pesquisador chamasse de "pragmática"'. Esse fato, facilmente comprovado até nos dias de hoje, inclusive no Brasil, pode ser considerado como o terceiro fator mais importante quanto à dificuldade em averiguar o "state of the art" em pragmática. Em conferência proferida por ocasião da $48^{\mathrm{a}}$ reunião anual da SBPC realizada em São Paulo, Marcuschi (1996) lamenta o quadro confuso que encontrou quando se propôs a fazer um levantamento sobre o interesse dos pesquisadores nas diferentes subáreas da Lingüística. A frustração do autor, contida no seguinte desabafo, ilustra bem o estado de coisas. Eis as suas próprias palavras (Marcuschi, 1996: 21-2):

É possível que eu não seja a pessoa mais indicada para classificar essa massa de dados. Há muita coisa que imaginei ser da área de Teoria Literária, Teoria da Cultura ou outras Teorias. Posso honestamente garantir que me esforcei para não falsear a visão dos fatos. Confesso também que as caracterizações [como elas se encontram feitas] não me agradam, pois elas mascaram os fatos. 
Há mais trabalhos de sintaxe e fonologia do que se imagina, mas eles são autocaracterizados como lingüística indígena (descrição fonológica, sintática) ou, então, psicolingüística (aquisição da sintaxe, da fonologia). Não há nada que se caracterize ou que se identifique de maneira explícita com semântica ou pragmática. Mas muitos dos trabalhos estão impregnados de semântica e pragmática. Não, porém, de uma forma mais técnica e teoricamente centrada. (ênfase acrescida).

$\mathrm{O}$ autor prossegue apontando que a mesma indefinição pode ser encontrada nos resumos dos seminários da ANPOLL, dos congressos da ABRALIN, e nas programações e nos Anais do GEL.

Um excelente indicativo da confusão que paira sobre a questão da delimitação das subáreas dentro da lingüística é a grande divergência entre os estudiosos no que diz respeito à proximidade entre elas ou mesmo as possíveis relações hierárquicas. Enquanto para Orlandi (1996: 33) há uma "diferença fundamental" entre a pragmática e a análise de discurso, diferença esta que estaria ligada à "própria noção de discurso", na ótica de Possenti (1996: 72), "A inclusão ou exclusão, em uma teoria do discurso, de pontos de vista da pragmática, da história ou da psicanálise não é obviamente uma questão simples: nem se deve crer que seja ditada pelos fatos, o que seria empirismo grosseiro, nem que seja ditada exclusivamente pela decisão do pesquisador de favorecer uma hipotética pureza teórica. Trata-se, em geral, de uma questão de política de conhecimento". Há outros pesquisadores que preferem seguir uma certa tradição já consagrada que apela para a noção de contexto para separar a pragmática da semântica. É preciso acrescentar no entanto que a própria noção de contexto é um tanto complexa e cabeluda. Moura (1999) sintetiza bem o problema inerente à prática de dividir o bolo de significação entre a semântica e a pragmática com base no conceito de contexto. Em suas palavras, "A fronteira entre semântica e pragmática é normalmente traçada a partir da noção de contexto. A significação que depende de contexto é colocada no campo de pragmática; o problema é que uma definição precisa de contexto raramente é fornecida, e a divisão entre semântica e pragmática continua muito fluída."(Moura 1999: 66). Na medida em que dão a entender que a subárea mais abrangente seria a análise de discurso (na qual pensar-se-ia a possibilidade ou não de incluir os pontos de vista da pragmática), Castilho e Altman (1994: 34) parecem entender a relação entre as duas áreas de forma exatamente oposta. Em suas próprias palavras, "Várias áreas de atuação se somaram ao "núcleo duro" da Fonética e da Fonologia, da Morfossintaxe e da Semântica, e hoje o 
país conta com especialistas respeitáveis atuando na Sociolingüística, na Psicolingüística, na Lingüística Indígena (ou Antropológica), na Pragmática (com seus ramos Análise do Discurso, Análise da Conversação, Lingüística do Texto)" (ênfase acrescida). Dascal (1982: 20), por sua vez, entende que o estudo lingüístico do texto (a ênfase é do referido autor) "está intimamente ligada à temática da pragmática". "Se ampliarmos," diz ele (Dascal 1982: 21), “.... a noção de 'contexto de enunciação' de modo a fazê-la conter também, o que parece natural, o contexto verbal (enunciados anteriores e posteriores) em que se insere o enunciado investigado, será fácil entrever como se liga a pragmática, enquanto investigação de todos os aspectos do 'contexto' que influem na interpretação de um enunciado, com o estudo do 'texto' (seqüência mais ou menos longa de enunciados).

Talvez a maior divergência entre os lingüistas que atuam na área de pragmática seja na questão da necessidade ou não de demarcar - e, se a resposta for "sim", como traçar - a linha divisória entre a pragmática e a semântica. É bom lembrar, antes de mais nada, que até pouco tempo atrás, a palavra "pragmática" simplesmente não constava dos programas e nomes das disciplinas dos cursos de pós-graduação em lingüística nas universidades brasileiras. Tópicos como a teoria dos atos de fala, a teoria de conversação de Grice etc. que, quase unanimemente são considerados como estando dentro da alçada da pragmática se encontravam como parte do conteúdo da disciplina de semântica. No caso da Unicamp, a "emancipação" da pragmática como disciplina separada da semântica ocorreu relativamente recente - não obstante afirmativas como a de que "O crescimento da produção em campos como os da Psicolingüística, Semântica(s), Pragmática(s), linhas de investigação que desde a fundação da IEL [Instituto de Estudos da Linguagem, unidade que abriga o Departamento de Lingüística na Unicamp] se prenunciavam fortes, acompanhou-se de significativa revisão - empírica e teórica - dos limites extensionais da análise lingüística e dos aspectos a ela pertinentes" (Altman, 1998: 219). Assim, na nota informativa sobre o departamento e seus cursos que consta do primeiro número dos Cadernos de Estudos Lingüísticos da Unicamp, não há sequer uma menção da palavra 'pragmática' e, das 29 dissertações de mestrado até então defendidas, apenas uma, a do Prof. João Wanderley Geraldi, ostenta a palavra em seu título Se a Semântica fosse também Pragmática ... ou Para uma Análise Semântica dos Enunciados Condicionais (Mesmo assim, o que o título efetivamente promete é um tratamento semântico do fenômeno sob enfoque).

Num trabalho apresentado na reunião anual da S.B.P.C. em 1982, 
Gomes de Matos (1982) observa a ausência da pragmática como disciplina na grande maioria dos programas de pós-graduação em todo o território nacional. As disciplinas mais compartilhadas eram, segundo o autor, fonologia, sintaxe, semântica, e teorias lingüísticas. Ao analisar as dissertações até então defendidas em 4 mestrados de universidades brasileiras - as universidades escolhidas foram a PUC-SP, a UFSC, a UFMG, e a UFPE, descobriu-se que, de todas as dissertações, apenas 2 lidavam com a pragmática, sendo uma da PUC-SP e a outra da UFPE.

É preciso deixar claro que, o que se verifica nas universidades brasileiras acerca da indefinição do conteúdo da pragmática enquanto disciplina autônoma é simplesmente um reflexo de uma tendência há muito em evidência na Europa e nos Estados Unidos. Trata-se da tendência de relegar a pragmática a um segundo plano, ou considerá-la como um apêndice da semântica. Na França, a escola que surgiu sob inspiração de Ducrot, chega a pleitear uma "pragmática integrada", ou seja integrada à semântica (cf. Ducrot, 1977; Vogt, 1977). Do outro lado do Canal da Mancha, Kempson (1977) defende uma semântica bem mais "magra", fiel às condições de verdade, implicações e acarretamentos lógicos etc. e, quase no desfecho do seu livro, confessa que "Não há dúvida de que a Cinderela deste livro tem sido a área de pragmática" (Kempson, 1977: 192). Aqui no Brasil, o livro de Ilari e Geraldi (1985) opta por uma divisão de bolo nessa mesma linha. Os fenômenos como sinonímia, antonímia, hiponímia e duplicidade de sentido são tratados como "temas semânticos mais tradicionais" (p. 41), ao passo que alguns fenômenos que são amplamente reconhecidos como pertencentes ao campo da pragmática (ver, por ex., Lobato 1987: 130) - tais como dêixis, atos de fala, implicaturas conversacionais, e até mesmo operadores argumentativos - são tratados sob o rótulo dos "fenômenos que demonstram a 'presença do homem na língua' " (expressão devidamente creditada a Émile Benveniste). Cabe lembrar também que, ao se debruçar sobre alguns aspectos sintáticos da sentença imperativa no português brasileiro, Faraco (1986:14) chama a atenção para "um processo interessante de mudança lingüística no português - que poderíamos chamar tentativamente de especialização pragmática".

A indefinição quanto à demarcação da linha fronteiriça entre os domínios da semântica e da pragmática também geraram algumas polêmicas interessantes. Em duas dessas, já bastante comentada na literatura, o presente autor teve participação. As duas polêmicas estão registradas nos seguintes conjuntos de três artigos cada: Rajagopalan (1983a), Kato (1983), e Rajagopalan (1983 b); Ilari (1984/1987), Rajagopalan (1987), Ilari (1987a). A primeira polêmica 
teve como pomo de discórdia os casos de verbos performativos no negativo, ao passo que a segunda se deu em relação às construções simétricas. Esses e outros autores deram vazão à constante preocupação no sentido de separar a semântica da pragmática, mesmo reconhecendo que os problemas se avolumavam de todos os lados. Houve também propostas mais categóricas e taxativas. Entre elas está a seguinte colocação de Perini (1985a: 46): "O estudo do significado literal é geralmente chamado "semântica"; o estudo dos fatores que modificam esse significado literal (para aqueles que colocam assim a questão) é colocado na "pragmática". Perini se apressa para acrescentar o seguinte: "Não existe critério universalmente aceito para distinguir pragmática de semântica; e nenhum dos critérios correntes é realmente preciso".

Com base em dados recolhidos nos Cadernos de Estudos Lingüísticos (CEL) da Unicamp, Altman (1998: 227) distingue 3 tendências nos estudos de significação. "Em última instância," acrescenta a autora, "a pertinência da chamada dimensão pragmática da linguagem, na análise semântica das línguas naturais, pode ser apontada como o grande divisor das águas das principais orientações - e também das principais polêmicas - que surgiram nos CEL, durante o período". A primeira tendência, segundo Altman, é centrada na análise gramatical e vê na pragmática "um papel marginal'. Pertencem a essa tendência Dascal (1982b), Ilari (1981, 1987), Francesconi (1982), Ilari e Mantoanelli (1983) e Gallego (1987). Como mote dessa tendência, Altman (1998: 227) cita as seguintes palavras de Ilari: “... o apelo a soluções pragmáticas [em muitos casos] vale por uma busca intuitiva, legítima, dos fatores que determinam as diferenças de leituras, e como maneira ilegítima de desobrigar-nos de representar tais fatores nas expressões produzidas pela sintaxe..." (Ilari, 1981: 57). A segunda tendência a que refere Altman também é centrada em categorias gramaticais porém "procura incorporar, à diferença da anterior, componentes pragmáticos na elaboração de uma teoria semântica". (Altman, 1998: 228). Os trabalhos citados como representantes dessa tendência são: Vogt (1978), Guimarães (1985), Tfouni (1984) e Fuchs (1985). A terceira tendência "seria englobante em relação à sintaxe e à semântica" e, segundo Altman, tem como representantes Rajagopalan (1984, 1987), Parret (1984), Jacques (1985), Lorenz (1986) e Dascal (1986).

Os dados de Altman, utilizados no parágrafo anterior, se referem à revista da Unicamp (Cadernos de Estudos Lingüísticos). As polêmicas entre as três tendências por ela distinguidas também foram travadas tendo a revista D.E.L.T.A como palco. Müller (1988) e Ilari (1987) são exemplos disso. Aliás, no âmbito da revista D.E.L.T.A., foram diversos os confrontos entre os 
partidários de formalismo e aqueles que pleiteavam apelo a fatores externos incluindo contexto de enunciação, funções comunicativas etc. Essas polêmicas na verdade se confundem com as polêmicas sobre os respectivos méritos da semântica e da pragmática. É possível argumentar que a própria polêmica "formalismo vs. funcionalismo" tem muito a ver com a questão da pragmática compreendida sob um certo prisma. Trata-se da tendência de identificar a pragmática com tudo o que diz respeito ao uso da língua em oposição à gramática (leia-se sintaxe, acrescida de uma interpretação semântica). Uma vez colocada nesses termos, a demarcação entre a gramática da forma e a pragmática do uso (ou das funções) vai ser feita em uma das seguintes maneiras: (a) defendendo uma gramática enxuta, repleta de regras determinísticas com "output" satisfatório sempre garantido; à pragmática cabe, neste caso, explicar tudo o que não se explica na gramática (b) propondo uma gramática bastante ampla, "frouxa", com muitas regras probabilísticas, heurísticas, e estocásticas; boa parte da pragmática é, dessa forma, incorporada à gramática.

A polêmica entre Perini (1985) e Kato (1985), logo no primeiríssimo número da D.E.L.T.A., exemplifica o confronto entre as duas opções (a) e (b) acima referidas. Enquanto Perini defende uma "gramática adaptada para as necessidades de comunicação", Kato prefere que os fatos analisados por Perini sejam analisados "como um fenômeno de uso". Da mesma forma Naro e Votre (1989) advogam uma postura eminentemente funcionalista como alternativa à abordagem formal, a qual é rechaçada por Nascimento (1990) com base num argumento de que as duas propostas são incomensuráveis, argumento este que é reforçado por Dillinger (1991). Naro e Votre definem seu objetivo da seguinte forma: "A hipótese fundamental desta proposta é que do uso da língua - a comunicação na situação social - origina-se a forma da língua, com as características que lhe são peculiares, inclusive, diferentes graus de instabilidade associados a diferentes subsistemas. Isso supõe entender a língua como um objeto maleável, probabilístico, e não nãodeterminístico" (Naro e Votre, 1989: 169-70). Utilizando uma metáfora que é atribuída a Redford, Nascimento diz: “... uma perspectiva de uso da língua está para o manual do construtor assim como o gerativismo está para as leis que regulamentam as construções. Isso quer dizer que a teoria apenas estabelece os princípios segundo os quais uma sentença é ou não bem formada, sem nada dizer sobre os usos que o falante faz dentre as formas autorizadas pela teoria" (Nascimento, 1990: 95). Convém lembrar que a posição de Nascimento se assemelha à de Kato que, em sua resposta a Perini, argumentara que "As formas que Perini considera agramaticais são, dentro dessa concepção, vistas apenas como não-ocorrentes ou não produtivas. Como fenômenos de uso e 
não de regra gramatical ..." (Kato, 1985: 119). Há, porém, uma importante diferença entre eles. Enquanto Nascimento considera formalismo e funcionalismo abordagens distintas e não necessariamente conflitantes entre si, Kato parece entender que há uma escolha a ser feita entre as duas alternativas. Por sua vez, Naro e Votre também não acreditam que a escolha entre as duas seja uma mera questão de gosto pessoal, mas sim algo a ser feito com base nos resultados concretos e mais satisfatórios - embora, diferentemente de Kato, sua preferência seja a favor da abordagem funcional.

Com base em Dik (1981), Neves (1994) contrapõe o paradigma formal (PFO) ao paradigma funcional (PFU) e explicita nada menos que 8 "tópicos de confronto" mais tarde "transfor[mando] sete desses tópicos em sete questões". A questão sete, tal qual é elaborada por Neves (1994: 69), interessa à presente discussão.

Qual a relação entre a pragmática, a semântica e a sintaxe?

No PFO, a sintaxe é autônoma com respeito à sintaxe [sic - creio que trata-se de um erro de datilografia, a autora, ao que parece, quis dizer, semântica]; a sintaxe e a semântica são autônomas com respeito à pragmática; as prioridades vão da sintaxe à pragmática, via semântica.

No PFU, a pragmática é vista como o quadro abrangente no qual a semântica e a sintaxe devem ser estudadas. A semântica é instrumental em relação à pragmática e a sintaxe é instrumental em relação à semântica. Nessa visão não há lugar para uma sintaxe autônoma.

Em trabalho publicado dois anos mais tarde, a autora coloca a questão nas seguintes palavras: "Na gramática funcional, noções 'pragmáticas' relativas às escolhas que o falante faz para distribuir a informação de seu enunciado - são entendidas como internas à gramática. Essa visão, que necessariamente relaciona padrões discursivos a padrões gramaticais, faz uma integração da pragmática na gramática" (Neves, 1996: 34). Cabe salientar que os formalistas rechaçam qualquer tentativa de incorporar fatores pragmáticos à gramática. A primeira pergunta que foi feita a Chomsky após sua conferência "Novos horizontes no estudo da linguagem" proferida no Rio de Janeiro em dezembro de 1996 foi "Por que o senhor parou de usar o termo sintaxe?" (cf. Chomsky, 1997: 73). Em sua resposta, Chomsky diz, entre outras coisas, o seguinte: 
Em minha opinião praticamente tudo o que se denomina semântica é sintaxe. Tem a ver com alguma coisa que está passando dentro da cabeça. Com representações internas que são objetos simbólicos e como interagem e assim por diante. [.....] as pessoas que estivessem trabalhando com a verdadeira semântica estariam falando da relação entre o que está na cabeça e o que está lá fora no mundo, as coisas sobre as quais as pessoas falam. Quase ninguém trabalha sobre isso. É um problema muito difícil. Aquilo com que as pessoas trabalham é a relação entre o que está dentro da cabeça e a maneira como é interpretado.

Voltando ao artigo de Neves, a autora concorda com Nascimento (1990) que "não cabe considerar uma ou outra como melhor opção, pelo simples fato de que cada uma tem diferente objeto de estudo, e, a partir daí, diferentes pressupostos, objetivos, e metodologia". Contrariamente à situação verificada com respeito a Kato e Naro / Votre, onde ambos estão de acordo sobre a necessidade de se fazer uma escolha, mas divergem quanto à escolha, Nascimento e Neves não vêem a necessidade de conflito de interesses entre formalismo e funcionalismo, embora cada um tenha sua preferência por uma das opções teóricas distintas. De modo geral, os pesquisadores que pleiteiam pluralismo na lingüística concordam com Nascimento e Neves sobre a possibilidade de convivência pacífica e harmoniosa entre abordagens diferentes. Franchi (1994) e Borges Neto (1996) são exemplos ilustrativos. Borges Neto (1996: 5-6) defende a tese de complementaridade entre as diferentes "visadas" da seguinte forma: "Dado o grande número de relações que a linguagem mantém, não temos condições de decidir por onde é que vamos começar a abordá-la. Toda abordagem proposta vai [ser] sempre parcial e arbitrária. A palavra de ordem aqui é escolha. E escolher implica em deixar algo de fora".

De qualquer forma, é fato inegável que os simpatizantes da corrente funcionalista recorrem com freqüência à pragmática, como pode ser facilmente constatada por uma consulta à bibliografia representativa (cf. Mollica, 1994: 79; Brito: 1994:80). Alguns analistas de texto também reconhecem a importância de considerações pragmáticas em seu trabalho. Diz Martins (1993: 253): “Os pré-requisitos de coerência de um texto ou discurso [passam por] relações que são de natureza pragmática, embora, dependendo da análise, se passam priorizar outros níveis de relação como o semântico". Em entrevista concedida a Dutra (1993), Sandra Thompson reforça uma certa caracterização da pragmática segundo a qual ela deve se voltar a unidades maiores que a 
sentença. Em resposta a uma pergunta a respeito da tendência de usar o termo 'análise do discurso' como sinônimo a todas as análises que envolvem aspectos pragmáticos, a lingüista norte-americana diz o seguinte: "Há muita gente trabalhando já há algum tempo em pragmática. .... Acontece que há várias pessoas aqui que, embora se digam interessadas em pragmática, estão trabalhando unicamente ao nível da sentença isolada. Inventam sentenças e discutem essas sentenças à luz dos atos de fala, discutem seu significado e os contextos em que podem ser usadas. Eu acho esse enfoque um tanto limitado, porque não se observa o contexto real, de fato, desses dados lingüísticos ... esse não é enfoque empirista." (Dutra, 1993: 218). A importância de analisar dados autênticos também foi ressaltada por Mollica e Roncarati (1991).

Se a preocupação no sentido de trabalhar com dados recolhidos da vida realmente vivida pelos usuários de língua e não inventados pela imaginação fértil dos pesquisadores une a pragmática às áreas como análise de discurso, análise conversacional, lingüística de texto, e sociolingüística, é de se esperar que os pesquisadores que se interessam pela pragmática também se interessem pelas questões que são tratadas sob o rótulo de "lingüística aplicada". É interessante mencionar a esse respeito que a recém publicada Concise Encyclopedia of Pragmatics (Mey, 1998) contém verbetes como 'Lingüística aplicada', 'Linguiística aplicada - sociolingüística', 'Educação em Black English em Reino Unido/ nos Estados Unidos', 'Discurso', 'Análise de discurso e literatura', 'Discurso, ideologia e literatura', 'Lingüística emancipatória', 'Etnografia de fala', 'Functional sentence perspective' , 'Linguagem e poder', 'Gramatologia', 'Interlíngua', 'Linguagem como realidade social', 'Linguagem e sociedade”, Língua para fins específicos: pedagogia', 'Métodos de ensino de língua', 'Imperialismo lingüístico', 'Pragmática literária', 'Sociolinguiística', e 'Linguística de texto', entre outros assuntos. A grande variedade de assuntos tratados é prova de que a pragmática mantém vínculos com muitas outras disciplinas, assim como muitas das demais subáreas dentro da linguiística. Uma rápida consulta ao livro de resumos das comunicações apresentadas durante o $6^{\circ}$ Congresso Internacional de Pragmática em Reims, França, em 1998, evidencia o crescente número de pesquisadores na área, assim como a grande variedade de questões que os atraem. Por sinal, o tema central escolhido para o referido congresso foi 'Ideologia'.

Os possíveis pontos de encontro entre a pragmática e a lingüística aplicada, ambas definidas em termos amplos, foram sinalizados nas seguintes palavras de Mey (1993:286), que pede que a pragmática fique cada vez mais voltada às questões de interesse social: 
A questão de uma pragmática socialmente sensivel é intimamente ligada à relação entre a lingüística como uma 'ciência pura' e a prática de lingüística enquanto aplicada ao uso da linguagem pelas pessoas, ao que elas 'fazem com as palavras', para usar uma fórmula que está à beira de se tornar banal. Tradicionalmente, essa cisão na lingüística se redundou numa divisão da disciplina em duas alas principais que parecem não conseguir conversar entre si: a lingüística teórica e a lingüística aplicada.

Para Mey, uma pragmática socialmente sensível conseguiria superar a distância entre a parte teórica e a parte aplicada. Tentativas como as de Mey, como também as de Cameron et al. (1993), Rampton (1995, 1997), Fairclough $(1989,1992)$ de interrogar a lingüística teórica, procurando torná-la eticamente responsável e consciente das suas implicações ideológicas estão abrindo novos caminhos para os pesquisadores em pragmática. Com base nas propostas de Hymes (1980), Rampton argumenta que a própria atividade de construir teorias é algo que se processa no mundo real (cf. Rajagopalan,1999a $\&$ b). As seguintes palavras de Pennycook (1998: 24) são bastante eloqüentes:

Como lingüistas aplicados, estamos envolvidos com linguagem e educação, uma confluência de dois dos aspectos mais essencialmente políticos da vida. Na minha visão, as sociedades são desigualmente estruturadas e são dominadas por culturas $e$ ideologias hegemônicas que limitam as possibilidades de refletirmos sobre o mundo e, conseqüentemente, sobre as possibilidade de mudarmos esse mundo.

À guisa de conclusão, podemos dizer com segurança que a pragmática já se encontra numa fase bastante amadurecida. A indefinição quanto às suas linhas de fronteira não pode ser atribuída à falta de consolidação da área nos meios acadêmicos. Ao que parece, a indefinição é algo típico da própria natureza dessa subárea da linguística. Em sua introdução à coletânea de textos em pragmática, Dascal (1982: 7) chega a dizer que "uma das preocupações fundamentais dos 'pragmaticistas' é a de justificar a inclusão de um componente pragmático na teoria da linguagem'. Ou seja, não muito tempo atrás os pesquisadores que enveredavam pelo caminho da pragmática se viam na necessidade de se desculpar e reivindicar seu lugar junto com seus colegas que trabalhavam nas áreas supostamente mais nobres. Já se foi aquele tempo. Curiosamente, numa conferência proferida apenas 2 anos após a publicação do referido livro, Castilho (1984) faz um apanhado geral dos trabalhos 
desenvolvidos nos quinze anos anteriores sob a égide do GEL (Grupo de Estudos Lingüísticos do Estado do GEL) e observa que um dos três centros de interesse dos pesquisadores é "o da Pragmática e da Lingüística do Texto, nisto que parece configurar uma ruptura com os paradigmas vigentes e o começo de uma nova revolução na Lingüistica, com expansão de seus domínios para as áreas cobertas até aqui por outras disciplinas, tais como a Teoria e a Crítica Literária, a Estilística, a Retórica, a velha Filologia.” (Castilho, 1984: 13). Trata-se, portanto, de duas tendências opostas, uma de submissão e apologia, notada por Dascal, e a outra, de desafio e confronto, identificada por Castilho.

A futurologia é sempre um empreendimento arriscado, já que não se dispõe de nenhuma bola de cristal confiável. Mas, se dicas que o momento presente nos oferece querem dizer alguma coisa, dir-se-á que a pragmática poderá vir a ser a única ponte para estabelecer diálogos frutíferos com as disciplinas conexas, como já previam as palavras de Castilho.

Agradecimento

Sou grato ao CNPq pela bolsa-pesquisa n. ${ }^{\circ}$ 306151/88-0.

REFERÊNCIAS BIBLIOGRÁFICAS

Altman, C. (1998) A Pesquisa Lingüística no Brasil (1968-1988). São Paulo: Humanitas.

Borges Neto (1996) O pluralismo teórico na lingüística. Estudos Lingüísticos, XXV (Anais do GEL): 4-17.

Brito, C. (1994). Uma proposta funcionalista. Boletim da ABRALIN, 15: 80-87. CAMERon, D. et al. (1993) Ethics, advocacy and empowerment: issues of method in researching language. Language and Communication, 13: 81-94.

Castilho, A. T. de (1984). Quinze anos de Grupo de Estudos Lingüísticos do Estado de São Paulo. Estudos Lingüisticos, IX (Anais do GEL): 10-20. \& M.C.F.S. Altman (1994) Para a história da Associação Brasileira de Lingüística. Boletim da ABRALIN, 16: 21-37.

Сномsкy, N. A. (1997) Chomsky no Brasil. D.E.L.T.A., 13. n. ${ }^{\circ}$ Especial.

Dascal, M. (1982a) Introdução. Pragmática. Parte IV. Fundamentos Metodológicos da Lingüística. Unicamp: 7-22.

(1982b). Comecemos a acabar de começar. Cadernos de Estudos Lingüísticos, 3. Unicamp: 126-186.

(1986) A relevância do mal-entendido. Cadernos de Estudos Lingüísticos, 11. Unicamp: 199-217. 
Diк, S. (1981) Funcional Grammar. Dordrecht-Holland: Foris Publications.

Dillinger, M. (1991) Forma e função na lingüística. D.E.L.T.A., 7. 1: 395-407. Ducrot, O. (1977) Dizer e Não Dizer: Princípios da Semântica Lingüística. Trad. bras. São Paulo: Ed. Cultrix.

FARACO, C. A. (1986) Considerações sobre a sentença imperativa no português do Brasil. D.E.L.T.A., 2: 1-15.

FAIRCLOUgh, N. (1989) Language and Power. Londres: Longman. (1992) Discourse and Social Change. Cambridge: Polity. (1995) Critical Discourse Analysis: Londres: Longman.

FRANCESCONI, C. (1982) Further evidence for a compositional nature of aspects. Cadernos de Estudos Lingüísticos, 3. Unicamp: 92-125.

FrANCHI, C. (1994) Lingüística no Brasil: o pluralismo necessário. Conferência proferida no $1^{\circ}$ Congresso Internacional da ABRALIN.

Fuchs, C. (1985) A paráfrase lingüística - equivalência, sinonímia ou reformulação? Cadernos de Estudos Lingüísticos, 8. Unicamp:129-133.

Gallego, M. (1987) Um exemplo de modelo intencional. Cadernos de Estudos Lingüísticos, 12. Unicamp: 25-41.

Gazdar, G. (1979) Pragmatics: Implicature, Presupposition, and Logical Form. Nova Iorque: Academic Press.

Geraldi et al. (1985) Operadores de argumentação e diálogo. Cadernos de Estudos Lingüísticos, 9. Unicamp: 143-157.

Gomes De Matos, F. (1982) Pós-graduação em Lingüística no Brasil: orientações curriculares e output (dissertações). Boletim da ABRALIN, 3: 81-87.

Guimarães, E. (1983) Sobre alguns caminhos da pragmática. Série Estudos, 9. Sobre Pragmática: $15-29$.

(1985) Não só ... mas também - polifonia e argumentação. Cadernos de Estudos Lingüísticos, 8. Unicamp: 79-107.

Hymes, D. (1980) Speech and language: on the origins of and foundations of inequality among speakers. In: Language in Education: Ethnolinguistic Essays. Washington: Center for applied Linguistics: 19-61.

ILARI, R. (1981) Os reflexivos e a interpretação dos prossintagmas. Cadernos de Estudos Lingüísticos, 2. Unicamp: 56-156. (1983 / 1987) Dos problemas de imperfeita simetria. Ensaios Lingüísticos, 9. 1983: 94-120. Republicado em Cadernos de Estudos Lingüísticos, 13. Unicamp. 1987: 49-65.

(1987a) O que fazer quando '2+3' não é igual a ‘3+2': a semântica e a pragmática das construções simétricas em língua natural. Cadernos de Estudos Lingüísticos, 13. Unicamp: 97-105.

(1987b) Algo mais sobre não só mas também. D.E.L.T.A., 3: 111-5.

Ilari, R. e Geraldi, J.W. (1985) Semântica. São Paulo: Ed. Ática. 
Ilari,. R. e I. Mantoanelli (1983) As formas progressivas do português. Cadernos de Estudos Lingüísticos, 5. Unicamp: 27-60.

JACQUES, F. (1985) Do dialogismo à forma dialogada. Cadernos de Estudos Lingüísticos, 9. Unicamp: 23-48.

Lorenz, K. (1986) A intencionalidade e sua dependência da linguagem. Cadernos de Estudos Lingüísticos, 11. Unicamp: 57-64.

KAто, M. A (1983) A determinação da força ilocucionária de construções com performativo no negativo: réplica a Rajagopalan. Série Estudos, 9. Sobre Pragmática: $39-45$.

(1985) A complementaridade dos possessivos e das construções genitivas no português coloquial - réplica a Perini. D.E.L.T.A. , 1. n. ${ }^{\circ} 1 \mathrm{e}$ 2: $107-120$.

Kempson, R. (1977) Semantics. Cambridge: Cambridge University Press.

LoвAto, L. (1987) Resenha do livro Semântica por Ilari e Geraldi. D.E.L.T.A., 3.1: $127-135$.

Lyons, J. Semantics. Cambridge: Cambridge University Press.

Mautner, T. (org.) (1996) Penguin Dictionary of Philosophy. Londres: Penguin Books.

Marcuschi, L.A. (1996). Perspectivas da pesquisa lingüística no Brasil. Boletim daABRALIN, 19:15-25.

MARTins, E. J. (1993) Uma perspectiva pragmática de análise de texto. Boletim da ABRALIN, 14: 253-59.

Mey. J.L. (1993) Pragmatics. Oxford: Blackwell.

(1998) Concise Encyclopedia of Pragmatics. Oxford: Elsevier.

Mollica, M.C. (1994) Funções diferentes de 'variantes' ou eqüivalência semântico-funcional em variação. Boletim da ABRALIN, 15: 74-79.

e RonCARATI, C. (1991) Enfoques sobre amostragem em sociolingüística. D.E.L.T.A., 7. 2: 521-8.

Moura, H.M de M. (1999) Significação e Contexto: Uma Introdução a Questões de Semântica e Pragmática. Florianópolis, SC: Ed. Insular.

MüLLER, A L. de P. (1988) Semântica formal versus pragmática. D.E.L.T.A., 4.2: 183-192.

Naro, A e Votre, S.J. (1989) Mecanismos funcionais do uso da língua. D.E.L.T.A., 5.2: 169-184.

NASCiMENTO, M. do (1990) Teoria gramatical e 'mecanismos funcionais do uso da língua'. D.E.L.T.A., 6.1: 83-98.

Nehrlich, B. e Clarke, D.D. (1996) Language, Action, and Context: The Early History of Pragmatics in Europe and America, 1780-1930. Amsterdam: John Benjamins.

Neves, M.H.de M. (1994) A gramática funcional. Boletim da ABRALIN, 15: 
$67-73$.

(1996) A gramática de usos é uma gramática funcional. Boletim da ABRALIN, 19: 27-38.

Orlandi, E. P. (1996) Exterioridade e ideologia. Cadernos de Estudos Lingüísticos, 30: 27-33.

Parret, H. (1984) Pragmática. Cadernos de Estudos Lingüísticos, 7. Unicamp: 39-51.

Pennycook, A. (1998) A lingüística aplicada dos anos 90: em defesa de uma abordagem crítica. In: I. Signorini \& M. C. CAVALCANTI (orgs.) Lingüística Aplicada e Transdisciplinaridade. Campinas: Mercado de Letras: 2350.

Perini, M. (1985a) Para Uma Nova Gramática do Português. São Paulo: Ed. Ática.

(1985b) O surgimento do sistema possessivo do português coloquial: uma interpretação funcional. D.E.L.T.A.,1. n. ${ }^{\circ} 1$ e 2: 1-16.

Possenti, S. (1996) Pragmática na análise do discurso. Cadernos de Estudos Lingüísticos, 30: 71-84

Rajagopalan, K. (1983 a) Sobre a eficácia comunicativa dos verbos performativos no negativo. Série Estudos, 9. Sobre Pragmática: 30-38.

(1983 b) O caso de verbos performativos no negativo: semântica ou pragmática? - Tréplica a Mary Kato. Série Estudos, 9. Sobre Pragmática: 46-65.

(1984) A note on His Majesty's baldness. Cadernos de Estudos Lingüísticos, 6: 219-227.

(1987) Quando “2+3” não é igual a “3+2": a semântica e a pragmática das construções simétricas em língua natural'. Cadernos de Estudos Lingüísticos, 13. Unicamp: 67-96.

(1996) Pragmática - uma vista aérea. Cadernos de Estudos Lingüísticos, 30: 5-7.

(1999a) Tuning up amidst the din of discordant notes: on a recent bout of identity crisis in applied linguistics. International Journal of Applied Linguistics, 9. n. ${ }^{\circ}$ 1: 99-119.

(1999b) Critical approaches and their raison d'être: a rejoinder to Brumfit and Widdowson. International Journal of Applied Linguistics, 9. n. ${ }^{\circ}$ : 127:134.

Rampton, B. (1995) Policies and change in research in applied linguistics. Applied Linguistics, 16 (2): 233-56.

(1997) Retuning in applied linguistics. International Journal of Applied Linguistics, 7 (1): 3-25.

TFouni, (1984) O resgate de identidade - investigação sobre o uso da 
modalidade por adultos não-alfabetizados. Cadernos de Estudos Lingüísticos, 7. Unicamp: 59-76.

Vogt, C. (1977) O Intervalo Semântico. São Paulo: Ed. Ática. (1978) Indicações para uma análise semântico-argumentativa das conjunções "porque", "pois" e "já que". Cadernos de Estudos Lingüísticos, 1. Unicamp: 35-50.

(1983) Pragmática: o rosto e a máscara da linguagem. Série Estudos, 9 Sobre Pragmática: 7-14. 